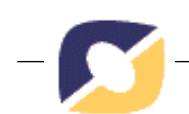

\title{
Trabalho de Conclusão de Curso (TCC) em um Curso de Graduação Modalidade EAD: uma Proposta Cooperativa Construída em Ambiente a Distância
}

\author{
*Luciane Magalhães Corte Real - FACED/UFRGS - lucreal@orion.ufrgs.br \\ Silvana Corbellini - silvanacorbellini@gmail.com
}

\begin{abstract}
Resumo: O presente artigo problematiza a construção de Trabalho de Conclusão de Curso (TCC) mediado por ambiente a distância (pbworks) em um curso de Graduação na modalidade a distância de uma Universidade Pública. Para tal fim foi utilizado o estudo de caso de um grupo de dez alunos pertencentes a um orientador. O objetivo da investigação foi aprofundar as relações interpessoais (presencial e/ou a distância) que podem estar presentes na orientação e suas implicações. O referencial teórico que norteou o trabalho foi a Epistemologia Genética Piagetiana e contribuições da Psicanálise Lacaniana, a primeira concebe a construção do conhecimento na interação do sujeito com o meio e a segunda, o inconsciente e as suas implicações na construção deste sujeito. Ambas as teorias partem do pressuposto de um sujeito ativo, autor de sua história. Constatou-se de que a orientação a distância, aliada a uma prática em cooperação, no sentido piagetiano, acrescenta valores ao trabalho científico como um todo, além de engendrarem novas formações de relações de trabalho, ampliando conhecimentos e integrando pessoas, enriquecendo, desta maneira a formação do docente.
\end{abstract}

Palavras chave: Educação a Distância; Trabalho de Conclusão de Curso; Piaget; Psicanálise

\begin{abstract}
The present article problematizes a construction of a course work conclusion mediated by a distance environment (pbworks) of a graduation course in a distance modality of a Public University. For this propose it was made a study of a group of ten students who belonged to an advisor. The objective of this investigation was to make deeper the interpersonal relations (in presence or by distance) that can be present in the orientation and its implications. The theoretical reference that leaded the work was the Piagetian Genetic Epistemology and the contributions of the Lacanian Psychoanalysis, the first concieves the knowledge construction of the individual with the envirornment, the latter the unconscious and its implications in the construction of this individual. Both theories start from the assumption of an active individual, author of his own history. It was noticed that a distance orientation, together with a practice in coordination, in the Piagetian meaning, adds values to a cientific work in a whole, also engender new formation in work relations, enlarging the knowledge and integrating people, enriching thus the formation of teachers.
\end{abstract}

Keywords: Distance Modality Education; Course Work Conclusion; Piaget; Psycoanalysis

\footnotetext{
Profa. Faculdade de Educação da UFRGS, Profa. do Curso de Pedagogia Modalidade a Distância PEAD/UFRGS. Doutora em Informática na Educação/PGIE/UFRGS.

** Profa. do Curso de Pedagogia Modalidade a Distância PEAD/UFRGS Mestre em Psicologia Clínica/PUCRS.
} 


\section{Apresentação}

Os cursos de graduação na modalidade a distância (EAD) tem sido um desafio na aprendizagem dos alunos e professores. Desafio este que faz parte da educação na modalidade presencial, mas toma diferentes contornos na EAD. A sala de aula presencial é substituída pela sala virtual em diversos espaços: ambientes de aprendizagem a distância ${ }^{1}$, wikis, blogs, fóruns, e-mails, lista de discussão, entre outros; as interações presenciais, ou seja, de corpo presente, tornam-se relações virtuais (no sentido de mediadas por ambientes a distância). A presença toma outra dimensão que não a corporal, e sim, a presença a partir da escrita, na interação nos diversos ambientes EAD.

Há necessidade de se produzir uma rede de saberes que se entrelaçam para produzir sentido e significados sobre a modalidade de ensino EAD. Essa rede de saberes em construção deve ajudar a tornar inteligível aos alunos e professores/tutores seus processos de aprendizagem e desenvolvimento, pois em EAD está em jogo relações mais flexíveis e fronteiras mais fluídas, ou seja, a possiblilidade de desterritorialização do aprender (Bitencourt 2009).

Os sujeitos envolvidos na educação mediada pelas tecnologias da informação e da comunicação (TICs) vivenciam situações críticas que afetam e tensionam os processos de aprendizagem tais como as posições de aprendente e ensinante e a aliança do aluno com o curso (Saraiva et all, 2006).

Oliveira (2009) examinando as especificidades de uso da inteligência lingüística na EAD analisa as dificuldades e necessidades de comunicação oral e escrita encontradas por gestores e aprendizes de cursos a distância. A autora refere que a inteligência lingüística é a que se manifesta e exercita no uso da linguagem e que pode ser de natureza verbal (falada ou escrita) ou não verbal (na codificação / decodificação / transcodificação de conteúdos diversos) na capacidade de usar a linguagem para convencer, estimular, comunicar informações, estabelecer, manter e romper contatos. Em EAD, a maioria do processo de comunicação entre os envolvidos se faz por meio do texto verbal escrito, o que pede, simultaneamente, habilidade de escrita e de leitura por parte de quem queira se comunicar bem nesse contexto. Assim como em vários outros contextos, em EAD. os espaços de malentendido e não entendido podem passar pela falta de proficiência lingüística em produzir, comunicar e receber/interpretar textos orais e escritos. Umas das altenativas apontadas pela autora são estratégias afetivas positivas por parte dos gestores, em que as experiências se revestem de prazer e de uma sensação de gratuidade que reforçam o clima motivacional indispensável à aprendizagem.

Zuin (2006) afirma que um dos grandes desafios em relação ao ensino a distância é o de fornecer condições para que os professores ausentes se tornem presentes, entretanto, refere que não se pode ser ingênuo a ponto de se acreditar que a presença física do professor garanta por si só o ensino de boa qualidade, pois em muitas ocasiões presenciais, prevalece o denominado pacto da mediocridade, no qual o professor finge que ensina e os alunos fingem que aprendem. No ensino a distância a presentificação do professor se faz por meio de sua "virtualização", ou seja, pela possibilidade de se espicaçar o desenvolvimento de um número cada vez maior de representações que estimulem os alunos a questionar os conteúdos transmitidos, os quais, ao invés de serem absorvidos, podem ser elaborados criticamente.

Pode-se pensar a questão presença/distância de uma outra forma sendo o operador "distância" um elemento constitutivo de todo processo educativo. A questão topológica colocada pela EAD a partir de novas coordenadas espaço-temporais deveria tão somente

\footnotetext{
${ }^{1}$ Cada ambiente de interação a distância possui suas peculiaridades, no caso de nossa experiência utilizamos um WIKI - pbworks.com - ambiente que possibilita edições de páginas com textos, figuras, vídeos, além de possibilitar uma troca ativa entre os participantes, tanto na edição como na possibilidade de comentários.
} 
trazer para a discussão o problema da distância presente em todo o processo educativo. Sem a distância entendida como a produção deste deslocamento de si não poderíamos falar de um processo educativo propriamente dito. A aprendizagem, mesmo quando nos referimos a uma educação presencial, não se dá necessariamente no espaço físico da sala de aula tradicional ou na presença do professor. Aprende-se no momento em que algo passa a fazer sentido: é aí que se produz um deslocamento e uma diferenciação em relação a si mesmo (Azambuja et all, 2010). A questão presença-ausência no ambiente a distância já foi tratada por Silva (2010) que refere a ideia de que educação "olho no olho" não implica uma presença participativa, ou seja, na situação presencial pode-se estar presente e ausente ao mesmo tempo. Neste sentido, podemos perceber que o "corpo presente" pode ser uma ilusão. A autora citada também trabalha a questão presença-ausência a partir da escrita. Em EAD a escrita tem um lugar privilegiado, pois impõe um outro tipo de materialidade da presença. Ao estilo psicanalítico, onde Freud postula o Fort $\mathrm{Da}$, em que com a partida/ausência da figura materna observada, a resposta elaborada pela criança é a representação deste movimento, através de uma brincadeira com um carretel de linha, em que a criança joga longe e puxa de volta, acompanhando esta brincadeira de vai e vem, pelas palavras Fort e Da. (Freud, 1920). Desta forma, o que ocorre é que a criança presentifica através da palavra a ausência materna. Da mesma maneira, simbolizando a ausência materna, tal qual, analogicamente falando, a escrita também pode tomar esta proporção simbólica.

Neste artigo apresentaremos a experiência da construção de Trabalhos de Conclusão de Curso (TCCs) em um curso na modalidade a distância (EAD) em uma universidade pública utilizando para orientação um ambiente a distância pbworks. Para isto, partimos de três pontos:

\section{a. A proposta do Curso de Licenciatura em Pedagogia na modalidade a Distância (PEAD/UFRGS) que consta no Guia Acadêmico (2007) e a construção do TCC}

O Projeto Político-Pedagógico do Curso, segundo o Guia Acadêmico (2007), se organiza em função de três pressupostos básicos: a autonomia relativa da organização curricular, considerando as características e experiências específicas dos aprendizes; a articulação do currículo entre si, nas distintas etapas e ao longo do curso e a relação entre práticas pedagógicas e a pesquisa como elemento articulador dos demais componentes curriculares.

Nas orientações quanto ao TCC o Guia Acadêmico (2007) refere que deverá ser constituído como um relato e análise de experiência, tendo como base as práticas realizadas nas escolas durante o estágio obrigatório. Neste contexto, o TCC deve ser o resultado de reflexão que integre a construção teórica e as experiências construídas ao longo do curso com as inovações pedagógicas realizadas durante o estágio curricular.

\section{b. Aprendizagem como Inter-Ação}

A proposta pedagógica do Curso é norteada pelo construtivismo piagetiano, então, é necessário esclarecer como é entendida a aprendizagem nesta perspectiva. A Epistemologia Genética de Jean Piaget estuda a gênese das estruturas cognitivas, explicando-a pela construção - daí construtivismo - mediante a interação radical entre sujeito e objeto. Assim parte de uma perspectiva interacionista em que "o conhecimento deve ser considerado como uma relação de interdependência entre o sujeito conhecedor e o objeto a ser conhecido, e não como a justaposição de duas entidades dissociáveis" (Inhelde, Bovet e Sinclair, 1977, p. 17). Para que a Inter-Ação se construa e a aprendizagem aconteça é necessário tanto uma construção cognitiva, como uma predisposição afetiva.

Real (2007) refere que Piaget (1954) esclarece as relações entre a vida intelectual e a afetividade em sua teoria. Faz uma analogia com o funcionamento de um automóvel que 
depende da gasolina para acionar o motor, mas esta não modifica a estrutura do carro. A afetividade pode impedir, provisoriamente, que um aluno compreenda determinado conteúdo ou estabeleça uma determinada relação com as regras, mas não interfere na configuração das estruturas cognitivas. A mesma autora cita que para Piaget (2001), o termo afetividade também designa os sentimentos propriamente ditos e, em particular, as emoções, bem como, as diversas tendências, incluindo as tendências superiores e em particular a vontade.

Desta maneira consideramos, neste artigo, a aprendizagem como Inter-Ação dependendo das estruturas cognitivas de assimilação e da predisposição afetiva à aprendizagem. A predisposição afetiva será apresentada como transferência (termo retirado da psicanálise e que será explicado posteriormente).

\section{c.Cooperação - operando com o outro}

Real (2007) refere que somente na medida em que o sujeito é capaz de se descentrar de seu ponto de vista, colocando-se no lugar do outro, armando uma possibilidade de cooperação - operar com - que o seu agir pode ser autônomo. Para que isto ocorra é necessária a construção do pensamento rumo à descentração e, por conseqüência, à operação, com a reversibilidade de pensamento que lhe é intrínseca, assim como, a possibilidade de engendrar relações de cooperação e a autonomia que essa implica. Esse processo só tem a possibilidade de acontecer nas relações coletivas ou, dizendo de outra forma, em vivências com o outro. A potencialidade produtiva das relações sociais tem sua máxima expressão nas relações de cooperação, ou seja, na capacidade pertinente às ações pelo fato de terem se tornado reversíveis, com as quais o sujeito adquire a possibilidade de agir cooperativamente, pois o outro, a partir disto, se faz presente como um igual, como passível de troca. Para Piaget (apud Real, 2007), a cooperação/autonomia pressupõe considerar o lugar do outro, lugar este que não está dado desde o início, mas é produto de uma construção. Já no plano social, a cooperação pode conduzir à prática solidária e à idéia de justiça, portanto a construção de valores. Da mesma forma, no plano intelectual, a cooperação abre possibilidades, ao liberar o sujeito de uma atitude egocêntrica, permitindo o acesso à lógica.

Para Piaget (1923, p. 74), "adaptar-se ao mundo social, como ao meio físico, é construir um conjunto de relações e situar-se a si próprio entre essas relações graças a uma atividade de coordenação, implicando a descentração e a reciprocidade de pontos de vista". Montagero e Naville (1998) referem que a noção de descentração dá conta da direção do desenvolvimento cognitivo. A princípio, a atividade cognitiva está submetida à ação própria e ao ponto de vista imediato. Posteriormente, ela se libera, de forma progressiva, de seus limites iniciais, graças à descentração, processo fundamental do desenvolvimento cognitivo. Essa noção é definida por oposição à de centração. Piaget entende por centração a fixação cognitiva nos objetivos imediatos da atividade pessoal isolada, a fixação na perspectiva própria e no que se apresenta com pregnância à percepção.

Desta forma, o que se apresenta como descentração é o processo de liberação do egocentrismo inicial. Permite a passagem de uma subjetividade deformante a uma objetividade relativa. Inserção de um ponto de vista próprio em um conjunto de pontos de vista possíveis e na inserção do eu em um universo do qual ele não é mais o centro. As coordenações que permitem as descentrações são, desta forma, ao mesmo tempo individuais e sociais. Descentrar remete também à capacidade de se desprender de um aspecto delimitado do real considerado até então, para se perceber outros aspectos e, finalmente, coordená-los entre si.

\section{Caminho metodológico}

Trata-se de uma pesquisa qualitativa na forma de estudo de caso de um grupo de 12 alunos pertencentes a um orientador de TCC. O universo do curso são 5 polos com um 
número de aproximadamente 70 alunos por pólo no curso em questão. Logo, são em torno de 5 orientadores por polo num total de 25 orientadores e 350 alunos. Neste caso específico, apresenta-se uma experiência de docência/discência, em um contexto de orientação de TCCs que foram construídos de forma diferenciada no curso em questão.

O objetivo geral desta pesquisa foi o de investigar as relações que foram sendo constituídas e as suas implicações neste percurso de um trabalho cooperativo.

O espaço de orientação constituiu-se em um wiki da orientadora (pbworks) com o wiki dos orientandos linkados nele. $\mathrm{O}$ wiki da orientadora apresentava as principais orientações relativas a construção de um TCC, tais como, os passos que ele deve conter, idéia de cronograma, parte do guia do aluno (do curso) com as orientações, como fazer referências (citações e bibliografia), a importância de um texto de autoria e recados importantes. A orientação propriamente dita foi realizada no próprio wiki dos alunos, sendo que após cada orientação os alunos abriam uma nova versão do trabalho (versão1, versão2, etc), mantendo desta forma os trabalhos anteriores.

A pesquisa documental, segundo Yin (2001), auxilia a evidenciar informações que foram obtidas por intermédio de outras fontes. Aqui, foram analisados, através de uma releitura atenta, os espaços de orientação assim como, os mails enviados pelos alunos em outros momentos do semestre. A ênfase recaiu nas inter-ações de orientadores e orientandos.

Em regra, os trabalhos de conclusão dos cursos de graduação são feitos via escolha por parte do aluno de um professor-orientador, sendo que este pode aceitar ou não. Neste caso específico, o processo ocorreu de uma maneira diferente. No oitavo semestre, que precedeu o TCC, foram formados grupos de 10 a 12 alunos para um orientador, sendo que o critério para a constituição destes grupos, foi a localização espacial dos alunos nos estágios curriculares ${ }^{2}$. Ao chegar o momento da orientação de TCC, os grupos continuaram os mesmos, sendo que houve modificações, apenas pontuais, quando necessário, como por exemplo: supervisor que saiu do Curso, aluno que trocou de pólo, etc. Nesta experiência específica que está sendo exposta, os trabalhos de conclusões têm uma característica singular, a de terem sido transferidos para uma outra professora orientá-los, com a qual, os alunos não haviam tido contato a priori. Isto ocorreu devido ao acúmulo de tarefas da professora orientadora responsável, que necessitou repassar algumas atividades para outra professora. Esta experiência possibilitou analisarmos de perto as relações que aconteceram entre alunos e orientadores e vice-versa.

As teorias psicanalíticas e piagetianas fundamentam a prática de orientação assim como, a análise dos dados deste estudo. A epistemologia genética concebe a construção do conhecimento na interação do sujeito com o meio e a teoria psicanalítica concebe o inconsciente e as suas implicações na construção deste sujeito. Ambas teorias partem do pressuposto de um sujeito ativo, autor de sua história.

"O estudo de caso, como estratégia de pesquisa, compreende um método que abrange tudo - com a sua lógica de planejamento incorporando abordagens específicas para a coleta de dados e para a análise de dados. Neste sentido, o estudo de caso não é nem uma tática para a coleta de dados nem meramente uma característica do planejamento em si, mas uma estratégia de pesquisa abrangente (YIN, 2001: P. 33)".

Com estes parâmetros iniciais, a construção de um trabalho de conclusão, as monografias do curso, foram evidentemente perpassadas, orientadas e construídas com estes paradigmas e via ferramentas tecnológicas.

\section{Relação professor aluno na construção do TCC}

\footnotetext{
${ }^{2}$ Cada pólo do curso abarca alunos de várias cidades vizinhas, assim, para que o orientador pudesse visitar seus orientandos de estágio com mais facilidade o grupo foi organizado pela proximidade das escolas.
} 
A proposta do trabalho de monografia do curso do PEAD era a de produção de um texto em que o sujeito, a partir de sua prática, produzisse uma discussão com os aportes teóricos que foram estudados no decorrer do curso. Ou seja, a necessidade era implicar a prática com a teoria, estabelecendo relações e entendimentos sobre o que foi realizado. Neste sentido, pode-se pensar, como uma proposta de inserir este discente, em uma metodologia de professor pesquisador, o que é sumamente necessário para dar conta das novas demandas da educação da nossa sociedade.

Stolzmann e Rickens (1999) referem que o que se transmite na escola não se encontra somente no aspecto de informações ou de conteúdos, mas, de uma operação que permite ao sujeito, ao entrar em contato com ideias, toma-las através de um árduo trabalho e reconstruilas, dentro de seu estilo, incorporando-as ao que já estava constituído e, como resultado, uma produção singular que reconhece como sua.

A transferência é uma manifestação inconsciente e, através dela, podemos aceitar ou rejeitar pessoas que estão ao nosso redor, sem conscientemente sabermos o por quể ${ }^{3}$.

A relação aluno-professor é estudada por vários autores a nível presencial e é pensada a partir da questão transferencial. Assim, podemos pensar conjuntamente com Kupfer (1997) de que o fenômeno da transferência está presente na relação educador-aluno, ocupando o lugar de sujeito-suposto-saber, mas sem que o mesmo, venha a encarnar esta atribuição. Ou seja, desta forma, ele permite a circulação do desejo de aprender.

Silva (2010) propõe pensarmos a função do professor como um provocador do desejo de saber dos alunos e menos um transmissor de conteúdos. Ainda aponta que esta posição pode ser mais interessante se considerarmos que atualmente, o acesso aos conhecimentos socialmente construídos não passa somente pela sala de aula, ou pelo docente, mas sim, que ele também pode ser mediado pelas tecnologias. Conclui dizendo que as possibilidades da instalação de uma transferência de trabalho são maiores, e que estas, possam propriciar que o aluno venha a construir sua própria pesquisa, singular, uma vez que o mestre abdica deste lugar de quem "domina" o saber. A autora desta forma aproxima através do conceito de incompletude, a Psicanálise e a Educação a Distância, ao qual, acrescentamos a teoria piagetiana.

\section{Relatando a experiência: alunos/orientadores}

Para situá-los descreveremos como ocorreram estes processos de encaminhamento das orientações. Estes trabalhos tiveram o seu início com a indicação do nome do novo professor orientador. Houve vários estilos de manifestação em relação a esta mudança, da qual, os alunos não foram consultados, mas sim comunicados, por contingencia do momento. Não havia outra alternativa que fosse viável no curto espaço de tempo que existia para o término dos trabalhos.

O processo transcorreu com cada sujeito, de uma forma singular, demonstrando o quanto o papel e a presença/ausência do professor em um processo de ensino-aprendizagem em educação a distância é fundamental para o estabelecimento de um laço. Então, algumas das manifestações que foram observadas inicialmente: a resistência de alguns orientandos de se dirigirem a nova orientadora, como por exemplo: a não inclusão da orientadora nova ao ambiente de orientação; o bloqueio por parte de outros à intervenção da antiga orientador, como observava-se que as mensagens enviadas não eram respondidas pelos alunos; alguns faziam a tentativa de conciliar as duas figuras, sendo que desta forma, os mails eram enviados com cópia para as duas orientadoras. Todas estas manifestações foram acolhidas, discutidas e trabalhadas conjuntamente pelas duas professoras orientadoras.

\footnotetext{
${ }^{3}$ Transferência: fenômeno que ocorre entre o paciente e o terapeuta, quando há deslocamento inconsciente dos sentimentos, desejos, afetos atribuídos a pessoas do passado para pessoas do presente, atualizando-os através da repetição.
} 
Desta maneira, o que se aponta em primeiro lugar, como o fundamental de um acolhimento é no sentido de que o professor orientador disponibilizou-se a colocar-se nesta função e mantendo uma presença mais efetiva, redirecionando desta forma a demanda e estabelecendo um laço transferencial, fruto de um encaminhamento que precisava chegar ao destinatário. Se pensarmos no quão difícil é o estabelecimento de um laço com alguém a quem escolhemos, nestes casos, a dificuldade é redobrada, pois esta demanda é redirecionada, requerendo cuidados para que este encaminhamento adquira a aceitação do novo componente.

A importância que se coloca na questão da relação é devido a um conjunto de fatores que estão implicados na construção de um trabalho de conclusão (ou qualquer outro trabalho intelectual): os afetivos, os cognitivos, os recursos físicos, materiais, etc. incluídos neste, a questão temporal. Para que o trabalho se constitua é necessário também, além de um tempo cronológico, o tempo de elaboração interna e estes dois tempos, nem sempre são coincidentes. Mas, existe um tempo de maturação interna, ou o tempo de compreender, conforme Lacan (1945) em que o sujeito vai construindo internamente as suas questões e também, as suas potencialidades para o ato, ou, para concluir, isto é, escrever.

O importante a salientar é de que este processo é um conjunto de ideias que se transforma em uma produção textual, e que demanda tempo e trabalho, tanto do orientando, quanto do orientador. Esta parceria é necessária para que se estabeleça um laço de trabalho e de confiança, onde o orientador possa intervir e o orientando possa receber as intervenções. Ou seja, este espaço da relação deve ser constituído numa via de mão-dupla e ser mantido nesta mesma via, com a retroalimentação de uma transferência baseada em trabalho. "O trabalho de orientação é um espaço nunca antes concedido ao aluno, um espaço no qual ele pode desenvolver as capacidades adquiridas mas raramente praticadas antes e, por essa razão tão simples, fadadas ao desperdício. (Bianchetti \& Machado, p. 57)"

Os alunos, ao chegarem à etapa de escrever um trabalho de monografia, no término de um curso, tiveram poucas experiências ainda de pesquisa, de produção própria. Por mais que no curso este processo tenha sido estimulado, é o primeiro trabalho que requer a autoria do aluno e o seu processo de criação.

Neste momento, o orientando, ou parte para o seu desenvolvimento e constitui a sua autoria, ou cede de suas questões, caindo na repetição, não ousando criar e se "expor" em sua escritura. Então, podemos pensar que neste momento, há uma inversão de lugares neste trabalho conjunto. Onde até então o professor era quem ocupava o "lugar de comando", dando as orientações, sugerindo leituras, reorganizando idéias; o orientando tende a "usurpar" este lugar, sendo ele que produz a partir de suas próprias organizações, seus estudos, sua pesquisa. Então, neste momento, o orientador "cede" o lugar ao orientando, em que ele passa a ser o mestre e autor de seu escrito, abdicando da posição de sujeito-suposto-saber.

Não existe um trabalho intelectual, uma pesquisa em que o mesmo não passe a fazer parte da vida do pesquisador. Ele fica imbuído e misturado ao seu objeto, o que corrobora com o paradigma de ciência de que não existe neutralidade, mas mais do que isto, ele realmente é incorporado ao pesquisador.

E se considerarmos, qual o estilo de "orientando/professor" que desejamos formar, há a necessidade de uma coerência por parte do "professor/orientador". Então, se a proposta da qual se parte é de uma epistemologia genética, ou do referencial psicanalítico, que sustente uma autoria, um sujeito ativo frente ao seu conhecimento, é preciso que este espaço de criação exista, que as letras possam brotar, unindo-se umas as outras, compondo a produção singular de cada pesquisador, um discurso científico, palpável e no qual o orientando vá adiante, pesquisando, construindo e reconstruindo os seus saberes.

A escrita de um trabalho é um processo individual. Cada sujeito tem que dar conta de sua produção. Ao mesmo tempo, há uma luz que o guia, o orientador. Esta é a função do 
orientador: iluminar. Iluminar para que o orientando, ao caminhar, encontre/construa o seu caminho.

Este trabalho conjunto, tal qual o procedimento analítico é sempre uma aposta: o analista aposta no analisando e decide conjuntamente com ele de ir a deriva, apontando, intervindo, sustentando o seu caminhar. Analogicamente, o procedimento de orientação em uma instituição de ensino também parte do mesmo pressuposto, o orientador aposta no orientando e caminham juntos. O importante, nos dois procedimentos, é de que a função do analista/orientador seja o de ser uma luz e que permita o caminhar do sujeito, até ele mesmo se iluminar. Salientando-se de que não importa o tamanho do passo, mas sim que ele seja dado.

Na perspectiva clinica, mais comumente é que a demanda parta do sujeito, diretamente para o analista. Na perspectiva institucional, hoje, na maioria dos casos, isto é uma possibilidade, de que o orientando escolha o seu orientador. $\mathrm{O}$ caso que expomos acima veio de um viés diferente, e por isto a sua importância e a sua originalidade. A necessidade de constituí-lo de uma outra maneira, com as suas peculiaridades, fizeram com que as professoras-orientadoras desenvolvessem uma parceria entre elas, juntamente com a professsora-tutora que acompanhava aos discentes em suas inquietações, sendo que muitas vezes, esta também fazia o papel de mediadora das angústias dos mesmos e também, os devidos encaminhamentos.

Desta forma, o que queremos mostrar é o percurso vivenciado e as implicações do mesmo, sendo que para tanto, nos aproximamos dos conceitos piagetianos, onde Piaget (1998) formula a questão da cooperação como um método construído na reciprocidade entre os sujeitos, decorrente da descentração intelectual e em que há construção de normas morais e racionais, sendo que a razão é considerada um produto coletivo.

Além disto, Piaget (1973) destaca a vinculação da cooperação à interação, a necessidade de formação de vínculos e a reciprocidade afetiva entre os sujeitos do processo ensino-aprendizagem. São estas interações, na visão do autor, que possibilitam a mudança do sujeito em sua estrutura, bem como dos componentes do grupo como um todo. Ou seja, há uma modificação no sistema de interações, acarretando novas formulações, propiciando com que os sujeitos possam resolver suas questões de forma diversa do que teriam feito sozinhos.

O contexto em que ocorreu este processo, foi em um ambiente virtual, nos Wikis dos orientandos e das orientadoras ou via e-mails. As trocas podem ser consideradas cooperativas em todos os níveis, ou entre todos os personagens envolvidos neste processo: professoresorientadores, professor-tutor e orientandos. A cooperação entre ambos fez com que o processo centrasse na produção do orientando, de forma que os encaminhamentos tomassem um rumo, apontando todos para a mesma direção, possibilitando desta forma que a orienta-ação, fosse feita, algumas vezes, por várias mãos, mas sempre de uma maneira complementar e com a mesma perspectiva.

Os instrumentos das tecnologias da informática desempenham importante papel no encaminhamento, no suporte destas relações, solucionando impasses, quase que instantaneamente, que de outra maneira seriam impossíveis. Ou seja, a mediação via tecnologia, propiciou um canal permanentemente aberto de trocas, de interações, de diálogos, de construções, entre professoras-orientadoras, professora-tutora e orientandos. Com o uso das ferramentas e do ambiente, todos os integrantes tinham acesso aos escritos uns dos outros, conseguindo desta forma, agregar ao trabalho do outro, sem modificar o rumo que estava sendo dado, ou seja, todos caminhavam para o mesmo objetivo, cada qual na sua função.

Com isto concluímos que é possível, não só a orientação a distância, mas também em cooperação, no sentido piagetiano do termo e que isto só acrescenta ao trabalho cientifico como um todo, bem como a formação do docente que se pretende, como cidadãos do mundo e participantes, integrando conhecimentos e pessoas a sua práxis. 
Importante salientar o quanto este percurso foi rico para todos, orientadores e orientandos, no sentido em que todos cresceram e principalmente a aprendizagem de um trabalho em conjunto, de um respeito mútuo, de construções contínuas e interligadas. Foram teias tecidas a várias mãos...

O conhecimento técnico na área, por parte do orientador, a sua prática, sua vivência, são aspectos fundamentais para o sucesso deste processo. Mas, de outro lado, o orienta-dor tem tanto a aprender com o seu orientando. Ele tem principalmente a aprender, do quanto ele tem a aprender.

E, ao término de um trabalho de orientação, há sempre acréscimos em ambos componentes. A transformação que se avista em um primeiro escrito, no esboço inicial de um orientando e o seu texto final é sempre surpreendente. Neste sentido, os relatos que ficam arquivados no ambiente virtual, são um recurso fundamental para a avaliação deste processo. Relembrar quantas histórias, quantas versões foram escritas neste meio-tempo, meio-espaço. $\mathrm{E}$, principalmente, nos darmos conta, de que nós não somos os mesmos que começamos esta empreitada: nem o orientador, nem o orientando.

\section{Considerações finais}

O professor orientador assume uma função importante no processo de escrita de um trabalho de conclusão, no qual ele não é apenas um mero espectador, mas podemos conceituar como um co-participante deste processo. Porque co-participante? Porque uma das funções, além de uma leitura/escuta atenta e flutuante, tal qual uma escuta analítica como nos propõe Freud, permite, através de pontuações, o relançamento do processo, promovendo ou não a sua continuidade.

Suportar este lugar requer que o docente-orientador esteja ciente de sua coparticipação e não de sua autoria. Estar atuante como uma função que o capacite a dar continuidade à produção, requerendo intervenções para que o autor-orientando não caia na inibição e deixe de produzir. Podemos, através de uma analogia, estabelecer um paralelo no qual o docente, ao intervir de uma forma inadequada, estabelece uma resistência na escrita, ou então um sintoma que causando a angústia também cause a interrupção do desenvolvimento do trabalho. No processo analítico, falamos de entrevistas preliminares, ou de um acolhimento do sintoma. No processo intelectual, em que o discente demanda uma orienta-ação de um orienta-dor, requer que este orientador, tenha condições de orientar-a-ação, ou seja, que ele possua habilidade para acolher, sustentar e encaminhar este trabalho.

Esta idéia é corroborada por Bianchetti e Machado (2002), onde através de sua pesquisa conclui:

\footnotetext{
"Diversos autores apontam para as interferências pessoais e subjetivas que irrompem na relação entre orientador e orientando durante o processo, e não raro os autores percebem que são chamados a exercer um papel quase terapêutico, nessa caminhada, sem no entanto, contarem com o preparo para tal função. Cabe dizer que o orientador, por estar no lugar daquele que lê e daquele que escuta, não deixa de se aproximar do lugar do terapeuta e se afasta do lugar do professor, que está, mais do que nada, para ser escutado pelo aluno. (p. 59)"
}

Estas resistências, que já fazem parte de um processo padrão de um trabalho de produção intelectual, neste caso específico, pensava-se que iriam ter maiores manifestações e desta forma, alguns cuidados foram tomados pelas professoras orientadoras.

Assim, desta maneira, as idéias piagetianas e psicanalíticas discutidas no texto, contribuíram para o sucesso desta caminhada. A necessidade dos orientandos em se sentirem assistidos, acompanhados e com, o manejo adequado das diversas situações transferenciais impostas nas relações, possibilitou que os todos estes discentes concluíssem o TCC no tempo 


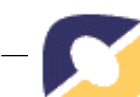

previsto e que os apresentassem publicamente a banca de avaliadores obtendo a devida aprovação.

O importante a destacar é de quanto às contribuições das teorias referenciadas, serviram de subsídios para as orientadoras neste trabalho, promovendo reflexões e avanços neste processo, possibilitando o êxito do mesmo, no sentido da observância de viabilidade de construção de uma prática diferenciada e cooperativa, agregando com isto, valores além dos aspectos profissionais, ou seja, valores sociais que foram agregados e, sem dúvida, ampliaram a formação destes docentes.

\section{Referências}

AZAMBUJA, Marcos e GUARESCHI, Neuza.¿Qué educación sería a distancia? Athenea Digital. Revista de Pensamiento e Investigación Social, Número 17, marzo 2010

BIANCHETTI, L e MACHADO (org.). A Bússola do escrever: desafios e estratégias na orientação teses e dissertações. Florianópolis: Ed. Da UFSC; São Paulo: Cortez, 2002. BITENCOURT, Ricardo. A educação a distância como estratégia de produção de novas identidades. Prometeus : Filosofia em Revista, 2009.

FREUD, Sigmund. Além do Princípio do Prazer. In: Obras psicológicas completas: Edição Standard Brasileira, Rio de Janeiro: Imago, 1920/1996.

Dinâmica da transferência. In: Obras psicológicas completas: Edição Standard Brasileira. Rio de Janeiro: Imago, 1912/1996.

INHELDER, BOVET e SINCLAIR. Aprendizagem e estruturas do conhecimento. São Paulo: Saraiva, 1977.

KUPFER, Maria Cristina. Freud e a Educação - o mestre do impossível. São Paulo. Editora Scipione, 1997.

LACAN. O tempo lógico e a asserção de uma certeza antecipada. In Escritos. Rio de Janeiro: Jorge Zahar, 1945/1998.

LAPOLLI, Edis Mafra. Tensões que afetam os espaços de educação a distância. Psicol. estud. [online]. 2006, vol.11, n.3, pp. 483-491.

LIPP, M. O stress do professor. Campinas: Papirus, 2002.

MONTAGERO e MAURICE-NAVILLE. Piaget ou a inteligência em evolução. Porto Alegre: Artes Médicas, 1998.

OLIVEIRA, Sheila. A inteligência Lingüística em educação a distância. Revista brasileira de informática na educação Ano:2009 Vol:14 Nr:2

PIAGET, Jean. Sobre a pedagogia. São Paulo: Casa do Psicólogo, 1998.

PIAGET, Jean. Estudos sociológicos. São Paulo: Companhia Editora Forense, 1973.

REAL, Luciane Magalhães Corte. Aprendizagem amorosa na interface escola - projeto de aprendizagem e tecnologia digital. Tese Programa de Pós Graduação em Informática na Educação/UFRGS, 2007.

SARAIVA, Luciana Martins; PERNIGOTTI, Joyce Munarski; BARCIA, Ricardo Miranda and SOLZMANN e RICKENS. Do dom de transmitir à transmissão do dom. Revista da Associação Psicanalítica de Porto alegre n 16, 1999 - ano IX; Porto Alegre: APPOA.

SILVA, Iranice Carvalho. Da Presença Virtual: Um estudo sobre a Transferência em Contexto de Educação a Distância.Tese de Doutorado em Educação - Universidade Federal do Rio Grande do Sul. 2010.

YIN, Robert K. Estudo de caso: planejamento e métodos. $2^{\circ}$ Ed. Porto Alegre: Bookman, 2001.

ZUIN, Antonio A. S.. Educação a distância ou educação distante?O Programa

Universidade Aberta do Brasil, o tutor e o professor virtual. Educ. Soc. [online]. 2006, vol.27, n.96, pp. 935-954. 